\title{
Conformational heterogeneity of Savinase from NMR, HDX-MS and X-ray diffraction analysis
}

\author{
Shanshan Wu ${ }^{1}$, Tam T T N Nguyen ${ }^{2}$, Olga V Moroz $^{3}$, Johan P Turkenburg ${ }^{3}$, Jens E Nielsen ${ }^{4}$, Keith S Wilson $^{3}$, \\ Kasper D Rand ${ }^{2}$, Kaare Teilum ${ }^{\text {Corresp. } 1}$ \\ 1 Structural Biology and NMR Laboratory, Linderstrøm-Lang Centre for Protein Science, Department of Biology, University of Copenhagen, Copenhagen N, \\ Denmark \\ 2 Protein Analysis Group, Department of Pharmacy, University of Copenhagen, Copenhagen Ø, Denmark \\ 3 York Structural Biology Laboratory, Department of Chemistry, University of York, York YO10 5DD, United Kingdom \\ 4 Novozymes A/S, Lyngby, Denmark \\ Corresponding Author: Kaare Teilum \\ Email address: kaare.teilum@bio.ku.dk
}

Background. Several examples have emerged of enzymes where slow conformational changes are of key importance for function and where low populated conformations in the resting enzyme resemble the conformations of intermediate states in the catalytic process. Previous work on the subtilisin protease, Savinase, from Bacillus lentus by NMR spectroscopy suggested that this enzyme undergoes slow conformational dynamics around the substrate binding site. However, the functional importance of such dynamics is unknown.

Methods. Here we have probed the conformational heterogeneity in Savinase by following the temperature dependent chemical shift changes. In addition, we have measured changes in the local stability of the enzyme when the inhibitor phenylmethylsulfonyl fluoride is bound using hydrogendeuterium exchange mass spectrometry (HDX-MS). Finally, we have used X-ray crystallography to compare electron densities collected at cryogenic and ambient temperatures and searched for possible low populated alternative conformations in the crystals.

Results. The NMR temperature titration shows that Savinase is most flexible around the active site, but no distinct alternative states could be identified. The HDX shows that modification of Savinase with inhibitor has very little impact on the stability of hydrogen bonds and solvent accessibility of the backbone. The most pronounced structural heterogeneities detected in the diffraction data are limited to alternative side-chain rotamers and a short peptide segment that has an alternative main-chain conformation in the crystal at cryo conditions. Collectively, our data show that there is very little structural heterogeneity in the resting state of Savinase and hence that Savinase does not rely on conformational selection to drive the catalytic process. 


\section{Conformational heterogeneity of Savinase from NMR, 2 HDX-MS and X-ray diffraction analysis}

3

4 Shanshan $\mathrm{Wu}^{1}$, Tam T. T. N. Nguyen ${ }^{2}$, Olga V. Moroz ${ }^{3}$, Johan P. Turkenburg ${ }^{3}$, Jens E. Nielsen ${ }^{4}$, 5 Keith S. Wilson ${ }^{3}$, Kasper D. Rand ${ }^{2}$, and Kaare Teilum ${ }^{1}$

$7 \quad{ }^{1}$ Structural Biology and NMR Laboratory and the Linderstrøm-Lang Centre for Protein Science,

8 Department of Biology, University of Copenhagen, 2200 Copenhagen N, Denmark

$9 \quad 2$ Protein Analysis Group, Department of Pharmacy, University of Copenhagen, 2100

10 Copenhagen Ø, Denmark

$11{ }^{3}$ York Structural Biology Laboratory, Department of Chemistry, University of York, York

12 YO10 5DD, UK

$13{ }^{4}$ Novozymes A/S, Biologiens Vej 2, 2800 Lyngby, Denmark

14

15 Corresponding Author:

16 Kaare Teilum

17 Ole Maaløes Vej 5, 2200 Copenhagen N, Denmark

18 Email address: kaare.teilum@bio.ku.dk 


\section{Abstract}

22 Background. Several examples have emerged of enzymes where slow conformational changes

23 are of key importance for function and where low populated conformations in the resting enzyme 24 resemble the conformations of intermediate states in the catalytic process. Previous work on the 25 subtilisin protease, Savinase, from Bacillus lentus by NMR spectroscopy suggested that this 26 enzyme undergoes slow conformational dynamics around the substrate binding site. However, 27 the functional importance of such dynamics is unknown.

28 Methods. Here we have probed the conformational heterogeneity in Savinase by following the 29 temperature dependent chemical shift changes. In addition, we have measured changes in the 30 local stability of the enzyme when the inhibitor phenylmethylsulfonyl fluoride is bound using 31 hydrogen-deuterium exchange mass spectrometry (HDX-MS). Finally, we have used X-ray 32 crystallography to compare electron densities collected at cryogenic and ambient temperatures 33 and searched for possible low populated alternative conformations in the crystals.

34 Results. The NMR temperature titration shows that Savinase is most flexible around the active 35 36 site, but no distinct alternative states could be identified. The HDX shows that modification of Savinase with inhibitor has very little impact on the stability of hydrogen bonds and solvent accessibility of the backbone. The most pronounced structural heterogeneities detected in the diffraction data are limited to alternative side-chain rotamers and a short peptide segment that has an alternative main-chain conformation in the crystal at cryo conditions. Collectively, our data show that there is very little structural heterogeneity in the resting state of Savinase and hence that Savinase does not rely on conformational selection to drive the catalytic process. 


\section{Introduction}

44 Subtilisins are serine proteases with broad substrate specificity that have found widespread use in 45 the laundry detergent industry. The 269 amino acid subtilisin from Bacillus lentus (Savinase) and 46 the homologous subtilisins from B. alcalophilus, B. amyloliquefaciens and B. subtilis are the 47 most studied proteins from this class (Betzel et al., 1992; Remerowski et al., 1994; Martin et al., 48 1997; Graycar et al., 1999; Mulder et al., 1999; Radisky \& Koshland, 2002; Tindbaek et al., 49 2004; Jones, 2011). The subtilisins comprise a structural family with an $\alpha / \beta$ fold and a 50 monomeric nearly spherical structure. The catalytic Asp/Ser/His triad is located in a groove on 51 the surface of the protein. The substrate binds in two large pockets of the groove thus positioning 52 the scissile bond in the active site. The substrate specificity is low but hydrophobic residues are 53 favoured at positions P1 and P4 of the substrate (Schechter \& Berger, 1967). In the structure of 54 Savinase, two structural metal binding sites are found to be occupied by $\mathrm{Na}^{+}$and $\mathrm{Ca}^{2+}$ (Frankaer 55 et al., 2014).

56 Analysis of fast protein dynamics by NMR spectroscopy previously demonstrated that the 57 structure overall is very rigid, but that the peptide segment 125 to 128 , which is involved in 58 substrate binding, is dynamic both on the time scale faster than nanoseconds as well as on the 59 time scale of milliseconds (Remerowski et al., 1996). In the same study increased dynamics were 60 also observed for residues 103 and 104 that cover the same part of the substrate binding site as 61 the 125-128 segment and which is thought to be important for controlling substrate access to the 62 binding site. These observations were supported by NMR relaxation and hydrogen exchange 63 measurements on the homologous subtilisin PB92 (Martin et al., 1997; Mulder et al., 1999).

64 With the improved sensitivity and resolution of techniques used for assessing protein dynamics, 65 several examples have appeared where conformational changes have been linked to specific 66 steps in the molecular mechanism of the protein function. Such NMR relaxation methods have 67 been used to characterize the conformational changes during catalysis in for example 68 dihydrofolate reductase (DHFR) (Boehr et al., 2010), cyclophilin A (Eisenmesser, 2002), 69 adenylate kinase (Wolf-Watz, Kay \& Kern, 2005) and trigger factor (Saio et al., 2018). By 70 following the temperature dependence of chemical shifts, NMR may also be used to probe the 71 existence of alternative states (Williamson, 2003; Teilum, Poulsen \& Akke, 2006; Doyle et al., 72 2016). Both the relaxation and temperature dependence of chemical shifts are sensitive to states 73 populated as little as 1\% (Williamson, 2003; Kay, 2016). The development of methods to 
74 analyse electron density near the noise level has provided great insight into alternative

75 conformational states of proteins and the conformational changes occurring during enzymatic

76 turnover (Fraser et al., 2009, 2011). Recent advances in liquid chromatographic systems, the

77 sensitivity of mass spectrometers, and MS data analysis tools have made HDX-MS a sensitive

78 and powerful tool to study conformational dynamics of proteins (Engen, 2009; Jensen \& Rand,

79 2016; Masson et al., 2019). These advances have revived the use of hydrogen exchange for

80 assessing local conformational dynamics with only minute amounts of proteins in solution (Fast,

81 Vahidi \& Konermann, 2017; Trabjerg, Nazari \& Rand, 2018) as well as in membranes (Möller et

82 al., 2019; Nielsen et al., 2019). Despite the great insight in the mechanism of many enzymes, the

83 existence of detectable conformational dynamics of importance for the catalytic mechanism is

84 not universal (Jensen, Winther \& Teilum, 2011).

85 Here we have asked the question if the conformational dynamics previously observed in

86 Savinase by NMR spectroscopy represents the existence of a specific conformational state that

87 potentially could be linked to the function of the enzyme. To probe the conformational

88 heterogeneity, we have followed the temperature dependent chemical shift changes, measured

89 changes in the local stability of the enzyme when an inhibitor is bound and finally analysed the

90 difference in electron densities from X-ray data collected at both cryogenic and ambient

91 temperatures. Our analysis reveals that Savinase overall has very little conformational dynamics

92 except for the substrate binding loops controlling the access to the active site that are more

93 mobile than the rest of the molecule.

94

95

96

97

98

\section{Materials \& Methods}

Protein production. Commercially available Savinase (Novozymes A/S) was dissolved in $0.1 \mathrm{M}$ dimethylglutaric acid, $\mathrm{pH}$ 6.5, $0.2 \mathrm{M}$ borate, $2 \mathrm{mM} \mathrm{CaCl}_{2}$ and run through a Sephadex G25 SEC column equilibrated in the same buffer. The sample was purified by ion-exchange chromatography on CM-Sepharose with a gradient from 0 to $100 \mathrm{mM} \mathrm{NaCl}$ in the above buffer as previously described (Betzel et al., 1988). The peak fractions were pooled and for storage the buffer was changed to $100 \mathrm{mM} \mathrm{H}_{3} \mathrm{BO}_{3}, 10 \mathrm{mM}$ 2-(N-morpholino)ethane sulfonic acid (MES), 2 $\mathrm{mM} \mathrm{CaCl}_{2}$, and $200 \mathrm{mM} \mathrm{NaCl}$ at $\mathrm{pH} 6$ by ultrafiltration. The expression media for the ${ }^{15} \mathrm{~N}$ (and 
$104{ }^{13} \mathrm{C}$ ) labelled samples was exchanged with $\mathrm{M} 9$ with $\mathrm{NH}_{4} \mathrm{Cl}$ as the sole nitrogen source (and U$105{ }^{13} \mathrm{C}_{6}$ glucose as the sole carbon source).

106

107

108

109

110

111

112

113

114

115

116

117

118

119

120

121

122

123

124

125

126

127

128

129

130

131

132

133

NMR sample preparation. For NMR, $10 \mu \mathrm{M}$ Savinase was incubated with $10 \mathrm{mM}$ PMSF in 20 $\mathrm{mM} \mathrm{Na}_{2} \mathrm{HPO}_{4}$-Citrate, $\mathrm{pH}$ 7. The mixture was incubated at $4^{\circ} \mathrm{C}$ for approximately 4 hours and subsequently filtered through a $0.2 \mu \mathrm{m}$ filter. The PMSF-inhibited Savinase was separated from unreacted PMSF, concentrated to $0.8 \mathrm{mM}$ and the buffer exchanged into $10 \mathrm{mM}$ $\mathrm{Na}_{2} \mathrm{HPO}_{4} / \mathrm{NaH}_{2} \mathrm{PO}_{4}, 2 \mathrm{mM} \mathrm{CaCl}, 1 \mathrm{mM}$ 4,4-dimethyl-4-silapentane-1-sulfonic acid (DSS), 10\% $\mathrm{D}_{2} \mathrm{O}, \mathrm{pH} 7$.

NMR experiments. All spectra were recorded on a Varian Inova $750 \mathrm{MHz}$ spectrometer and the data were processed by NMRPipe (Delaglio et al., 1995) and analysed using CCPNMR (Skinner et al., 2016). The backbone resonances for PMSF-Savinase were assigned from ${ }^{1} \mathrm{H}-{ }^{15} \mathrm{~N}$ HSQC, HNCA, HNCACB spectra recorded by reference to the published assignments of Savinase (Remerowski et al., 1994, 1996; Martin et al., 1997).

The temperature titration experiment was performed for PMSF-Savinase on a Varian Inova 750 $\mathrm{MHz}$ spectrometer. One dimensional ${ }^{1} \mathrm{H}$ spectra with presaturation and ${ }^{1} \mathrm{H},{ }^{15} \mathrm{~N}$ HSQC spectra were recorded in $2 \mathrm{~K}$ intervals from $289 \mathrm{~K}$ to $307 \mathrm{~K}$. The chemical shifts of the backbone amide protons at each temperature were measured to a precision of $0.001 \mathrm{ppm}$ relative to DSS. Firstorder and second-order polynomial models were fitted to the ${ }^{1} \mathrm{H}^{\mathrm{N}}$ chemical shifts versus the temperature. The F-test $(\mathrm{p}<0.05)$ was applied to determine significant deviations from linearity.

HDX-MS sample preparation. Samples of PMSF inhibited and isotope unlabelled Savinase were prepared as described above. Samples of uninhibited and isotope unlabelled Savinase were prepared by exchange of buffer into $300 \mathrm{mM} \mathrm{Na} 2 \mathrm{HPO}_{4} / \mathrm{NaH}_{2} \mathrm{PO}_{4}, \mathrm{pH} 7$ to remove the borate inhibitor. To start the HDX reaction, $50 \mu \mathrm{M}$ Savinase was mixed 1:20 with HDX labeling buffer (20 mM Bis-Tris, $10 \mathrm{mM} \mathrm{CaCl}_{2}$ in $99.9 \% \mathrm{D}_{2} \mathrm{O}, \mathrm{pD}=7.0$ ) at $25^{\circ} \mathrm{C}$. At time intervals of $0.25 \mathrm{~min}$, $1 \mathrm{~min}, 10 \mathrm{~min}$ and $60 \mathrm{~min}$, the exchange reaction was quenched by transferring $50 \mu \mathrm{l}$ of reaction stock into $50 \mu \mathrm{HDX}$ quench buffer $\left(300 \mathrm{mM} \mathrm{KH}_{2} \mathrm{PO}_{4} / \mathrm{H}_{3} \mathrm{PO}_{4}, \mathrm{pH}=2.3\right)$ at $0{ }^{\circ} \mathrm{C}$. The deuterated samples were immediately frozen and stored at $-80^{\circ} \mathrm{C}$ until the LC-MS analysis was performed. 
134 Fully deuterated samples of Savinase were prepared by incubation in $8 \mathrm{M}$ deuterated $\mathrm{GndHCl}$ $135\left(95 \% \mathrm{D}_{2} \mathrm{O}\right)$ overnight, and the reaction was quenched under the same conditions as above. For 136 preparing non-deuterated references, $50 \mu \mathrm{M}$ Savinase were mixed with the HDX buffer prepared 137 in $\mathrm{H}_{2} \mathrm{O}$ in a volume ratio of 1:24. The solution was diluted with the same volume of the HDX 138 quench buffer to obtain the final sample. The fully deuterated and non-deuterated samples were 139 stored at $-80^{\circ} \mathrm{C}$ until analysis.

Global HDX-MS experiments. Global HDX-MS analysis was performed on a combined HDXUPLC system with a Synapt G2 mass spectrometer (Waters). The temperature for the UPLC system was maintained at $0{ }^{\circ} \mathrm{C}$ and equipped with a $\mathrm{C} 4$ column trap (ACQUITY UPLC BEH C4 $1.7 \mu \mathrm{m}$ VanGuard column, Waters) and an analytical C4 column (ACQUITY UPLC BEH C4 1.7 $\mu \mathrm{m}$ column, Waters). The protein sample was desalted initially on the trap column with a flow rate of $200 \mu \mathrm{l} / \mathrm{min}$ mobile phase $\mathrm{A}\left(0.23 \%\right.$ formic acid in $\left.\mathrm{H}_{2} \mathrm{O}\right)$ for $3 \mathrm{~min}$ to remove buffer additives that may interfere with ionization. The protein was eluted with a 7 min gradient from $8 \%$ to $40 \%$ mobile phase B ( $0.23 \%$ formic acid in acetonitrile) for the ESI-MS at the rate of 40 $\mu 1 /$ min. The generated positive ions were analysed by the mass spectrometer in MS-only mode, with the scan range from $50-2000 \mathrm{~m} / \mathrm{z}$ per 1 second. Global HDX experiments were performed in duplicate.

152

Local HDX-MS experiments. Local HDX-MS analysis was performed on a combined HDXUPLC system with a Synapt G2 mass spectrometer (Waters). The temperature for the HDXUPLC unit was maintained at $0{ }^{\circ} \mathrm{C}$ and the system was equipped with a $\mathrm{C} 18$ column trap (ACQUITY UPLC BEH C18 $1.7 \mu \mathrm{m}$ VanGuard column) and an analytical C18 column (ACQUITY UPLC BEH C18 $1.7 \mu \mathrm{m}$ column). Deuterated and undeuterated proteins were digested on-line at $20^{\circ} \mathrm{C}$ as they passed the manually packed pepsin column (Pepsin agarose, Pierce). The resulting peptic peptides were desalted on the trap column with the flow rate of 200 $\mu \mathrm{l} /$ min mobile phase A. Peptic peptides were eluted with a 12 min gradient from $8 \%$ to $40 \%$ mobile phase B to the mass spectrometer for positive mode ESI at the rate of $40 \mu 1 / \mathrm{min}$. For peptide mapping, the mass spectrometer was operated in MSe (DIA) mode with CID fragmentation. The scan range was set to $300-2000 \mathrm{~m} / \mathrm{z}$ for MS and $50-2000 \mathrm{~m} / \mathrm{z}$ for MS/MS, with the scan time of $0.5 \mathrm{~s}$. For deuterated samples the mass spectrometer was operated in MS 
165 mode with a scan range of 50-2000 m/z and a scan time of 0.3 seconds. Local HDX experiments 166 were performed in triplicate.

167

168

Data Analysis. For intact mass analysis (global HDX-MS), the acquired spectra were

169

170

171

172

173

174

175

176

177

178

179

180

181

182

183

184

185

186

187

188

189

190

191

192

193

194

195 deconvoluted by MaxEnt in MassLynx 4.1 (Waters), and the resolution of deconvolution was set to $0.1 \mathrm{Da}$. For local HDX-MS analysis, peptides were identified by database searching using PLGS 2.5 (Waters). Analysis of peptide deuterium levels was performed using DynamX 3.0 (Waters). The final HDX processed data were exported directly from DynamX 3.0 to Pymol (Schrödinger) for illustration. The normalized deuterium uptake fraction is estimated by: Normalized $\operatorname{HDX}(\%)=\left(\left[m_{\mathrm{D}}-m_{\text {Non_D }}\right] /\left[m_{\text {Full_D }}-m_{\text {Non_D }}\right]\right) \times 100 \%$

Where $m_{\mathrm{D}}, m_{\text {Non_D }}$, and $m_{\text {Full_D }}$ are centroid masses of deuterated peptides at each time point, undeuterated peptides, and fully deuterated peptides under the current experimental settings, respectively. To allow access to the HDX data of this study, the HDX Data Summary Table (Supplemental Table S1) and the HDX Data Table (Supplemental Table S2) are included in the Supplemental Information according to the community-based recommendations (Masson et al., 2019).

Crystallization and Diffraction Experiments. The crystals for both room temperature (RT) and cryogenic datasets were picked from condition G2 of the PACT screen (Newman et al., 2005), 0.2 M NaBr, 0.1 M Bis Tris propane $\mathrm{pH}$ 7.5, 20\% PEG3350. X-ray diffraction data were collected at the Diamond Light Source beamline I03. The ambient temperature (RT data) were collected at $297 \mathrm{~K}$, and showed negligible radiation damage; the cryogenic data (cryo data) were collected at $100 \mathrm{~K}$. Images were integrated using XDS (Kabsch, 2010) and scaled with Aimless (Evans \& Murshudov, 2013).

Initial Structure Calculation and Refinement. Molecular replacement was performed using the published 1.4 Å resolution crystal structure of wild-type Savinase (PDB accession code: 4CFY) as the search model (Frankaer et al., 2014). Refinement was performed by PHENIX (Liebschner et al., 2019), to establish preliminary single-conformer structures for the RT and cryogenic crystals. 
196 Multi-conformer Ensemble Generation by qFit. For both the RT and the cryogenic data and 197 starting from the single-conformers structures, qFit (Keedy, Fraser \& van den Bedem, 2015) was 198 run to automatically construct multi-conformer models based on the observed electron density. A 199 few manual adjustments were made to the models after the automatic qFit model generation. 200 Five additional cycles of structural optimizations were performed using Phenix.refine with 201 occupancy refinement and automatic solvent-picking. No hydrogen atoms were added. The 202 models were refined with anisotropic B-factors except for water molecules.

203

204

Ringer Analysis for X-ray Electron Density Maps. The optimized $2 \mathrm{mF}_{\mathrm{o}}-\mathrm{DF}_{\mathrm{c}}$ density maps for 205 single-conformer models were calculated using Phenix.maps with a grid spacing set to 0.2 of the 206 resolution. The averaged side-chain conformation of the single-conformer models for each 207 residue was used as input for Ringer analysis (Fraser et al., 2009; Lang et al., 2010). The sidechain torsion angles were incremented in $10^{\circ}$ steps and compared to the electron density above $1 \sigma$ to build alternative side-chain conformations. The resultant multi-conformer models with alternative side-chain conformations were optimized using Phenix.refine, with the same refinement settings as for the refinement of the qFit models described above. The electron densities for residues with alternate conformations after the qFit and Ringer analyses were inspected in COOT and only those with convincing evidence for the alternate conformations were accepted for the final models.

\section{Results}

217 The broad specificity of Savinase makes it a substrate for itself. To prepare samples that are stable long enough for our NMR measurements it was necessary to inhibit the enzyme irreversibly. Using PMSF, we prepared homogenous samples that were stable for weeks. To complement the previous NMR relaxation and hydrogen exchange analysis we initially used NMR spectroscopy to follow temperature induced changes in chemical shifts. The temperature coefficients of the amide protons, ${ }^{1} \mathrm{H}^{\mathrm{N}}$, are sensitive to the presence of hydrogen bonds. Thus ${ }^{1} \mathrm{H}^{\mathrm{N}}$ that engaged in hydrogen bonds have $\mathrm{d} \delta / \mathrm{dT}$ more negative than $-4.6 \mathrm{ppb} /{ }^{\circ} \mathrm{C}($ Baxter \& Williamson, 1997; Tomlinson \& Williamson, 2012). In line with this, the least negative $d \delta / d T$ values are found in the loops and near the ends of $\alpha$-helices and $\beta$-strands. There is a tendency 
226 that the $\mathrm{d} \delta / \mathrm{dT}$ values on the face of the protein around the active site are slightly larger than on 227 the opposite side suggesting that the protein is most flexible around the active site (Figure 1). In 228 addition to be used as a measure of the strength of hydrogen bonds, the temperature dependence 229 of the chemical shifts may also probe the existence of low populated alternative states.

230 Divergence from linearity in plots of $\delta$ vs. T may thus result from a temperature dependent shift 231 in population of such alternative states (Williamson, 2003; Tomlinson \& Williamson, 2012). In 232 Savinase, most residues show linear temperature dependence of the chemical shifts, but for 14 233 residues there is significant $(\mathrm{F}$-test, $\mathrm{p}<0.05)$ but subtle curvature in the $\delta$ vs. T plots 234 (Supplemental Figure S1). These residues are, however scattered apparently randomly over the 235 protein. The NMR temperature titration suggests that Savinase is most flexible around the active 236 site (Figure 1C), but no distinct alternative states were identified.

237

238 For several enzymes it has been reported that conformational dynamics may be attenuated by 239 binding of inhibitors (Boehr et al., 2010; Masterson et al., 2012). We thus turned to HDX-MS to 240 assess if there is any change in the local stability when Savinase is inhibited by PMSF. In addition to the low amount of protein needed, the advantage of HDX-MS is that the experiment 242 time is short. Autoproteolysis is thus minimal in uninhibited Savinase and the HDX pattern can 243 be compared between active and inhibited enzyme.

244 Firstly, the total global HDX was measured on samples of uninhibited and PMSF-inhibited 245 Savinase. The HDX was very slow with $40 \%$ and $42 \%$ of the exchangeable hydrogens replaced 246 by deuterium, respectively, after $60 \mathrm{~min}$ of incubation at $\mathrm{pH} 7$ and $25^{\circ} \mathrm{C}$ where hydrogen 247 exchange is favoured (Supplemental Figure S2). Savinase thus has a stable core that rarely visits 248 an open state from which HDX can occur. This is in agreement with the crystal structure and 249 what would be expected from hydrogen exchange measured by NMR on the homologous PB92 250 subtilisin (Fogh et al., 1995).

251 To assign the HDX to different regions, Savinase was treated with pepsin before the MS 252 analysis. This treatment yielded 110 peptides covering $100 \%$ of the sequence of the uninhibited 253 enzyme, and 106 peptides covering 97\% of the sequence of PMSF-inhibited enzyme. In this way, local HDX profiles for uninhibited Savinase and PMSF-Savinase were generated covering the full sequence, except residues 209-216 in PMSF-Savinase (Figure 2). The resolution of the HDX data varies from single amides to stretches of 14 amides. In parts of the sequence, 
257 exchange occurs on the minute time scale. However, the segment from residue 123 to residue 258 133, where several labile hydrogens engage in hydrogen bonds in the structure, has almost fully

259

260

261

262

263

264

265

266

267

268

269

270

271

272

273

274

275

276

277

278

279

280

281

282

283

284

285

286

287

exchanged within $15 \mathrm{sec}$ suggesting that this part of the protein is flexible. At the other extreme, there are segments that show almost no exchange within 60 minutes, particularly evident for the segments 119-122 and 217-227. As expected, most of the slow exchanging regions include residues involved in secondary structures in the interior of the protein.

Overall the local HDX profiles of uninhibited Savinase and PMSF-Savinase (Figure 2 and Supplemental Figure S3) are very similar. We compared the data for the two situations by individual t-tests at each time point to determine if the deuterium uptake was significantly different. The results show only two minor differences were significant $(p<0.01)$ and that these were assigned to two peptide segments 147-168 and 184-190/191. These reductions in HDX upon PMSF binding were however very minor (Figure 2 and Supplemental Figure S3) and borderline with the normal limit of detection / confidence limit of the method (Trabjerg, Nazari \& Rand, 2018; Hageman \& Weis, 2019). The two segments 147-168 and 184-191 are located spatially close to each other and to the active site and thus could indicate a subtle local impact on the backbone dynamics in this region upon PMSF binding nearby.

It can therefore be concluded that modification of Savinase with PMSF has only a minor effect on the dynamics of the backbone that leads to exposure of amide groups. Hence, our NMR experiments performed on PMSF-inhibited Savinase should be indicative of the properties of the uninhibited native state of the enzyme. We note that the HDX-MS experiments were constrained to relatively short timescales due to issues with auto-proteolysis of the enzyme at longer timescales. HDX performed at longer timescales could potentially reveal differences between WT and PMSF-inhibited Savinase not detected here.

We next recorded independent sets of X-ray diffraction data recorded at room temperature and at cryogenic temperature. It has been demonstrated that cryo-conditions in some cases can favour conformations that are unfavourable at room temperature (Halle, 2004) and in other cases it has been demonstrated that minor conformations can be identified in high resolution electron density maps recorded at room temperature, which were not seen in the cryogenic data (Fraser et al., 2009, 2011). Savinase was crystalized in space group $\mathrm{P} 2{ }_{1} 2_{1} 2_{1}$ and diffraction data were collected 
288 to $1.1 \AA$ and $0.95 \AA$ resolution for the RT and cryogenic crystals, respectively. qFit and Ringer 289 were used to construct multi-conformer models of Savinase for both the RT and cryogenic 290 crystals (Supplemental Table S3). The structures derived from the crystals at room and cryogenic 291 temperatures are very similar, with an RMSD between the structures of $0.20 \AA$ and $0.37 \AA$ for 292 the backbone and all heavy atoms, respectively. The average $\mathrm{C}^{\alpha}-\mathrm{C}^{\alpha}$ displacement of the aligned 293 structures is $0.18 \AA$ and the largest displacement is $0.80 \AA$. Thus, the two structures show no 294 regions with major differences.

295 From the multi-conformer refinement, we find alternative conformations for 28 residues in the 296 RT structure and for 25 residues in the cryo structure (Supplemental Table S4). These alternative 297 conformations are different sidechain rotamers except for the peptide segment 128-132 which in 298 the cryo structure shows an alternative mainchain conformation (Figure 3A). Most of the 299 residues with alternative rotamers are serines (Figure 3B-C), 14/28 and 12/25 in the RT and cryo 300 structures, respectively. Except for the peptide segment 128-132 in the cryo structure and the 301 dipeptide 103-104 in both structures, the residues with alternative conformations are isolated in 302 the structure and do not appear to engage in any cooperative network of conformational change.

\section{Discussion}

305 We have demonstrated that Savinase, except for alternative rotameric states of 25 sidechains is 306 well described by a single conformation for the RT structure. In the cryo structure residues 128132 have an alternative mainchain conformation and this segment also appears particularly flexible from the HDX-MS analysis. We note that this segment is adjacent to the segment 125128, which together with residues 103 and 104 that have alternative conformations in both the RT and cryo structures appeared more dynamics than the remainder of the protein from NMR relaxation analysis (Remerowski et al., 1996). The loops lining the substrate binding site have 312 more negative chemical shift temperature coefficients, and even more clearly these parts of the 313 protein have the largest crystallographic B-factors (Figure 4). The B-factors, the temperature coefficients of the chemical shifts and the hydrogen exchange report on motions in the protein at 315 different time-scales and will therefore have maxima in different regions of the protein. This is 316 similar to the situation in other proteins where motions on different time-scales are observed in 317 different regions of the proteins (Pandya et al., 2018; Verteramo et al., 2019). 
318 The X-ray structures suggest that there was little to be gained through the qFit and Ringer 319 analysis of Savinase due to its rigidity, perhaps with the exception of the easy building of the 320 128-132 conformation in the cryo-temperature structure. However, the latter is not seen in the 321 isomorphous cryogenic 4CFY structure already in the PDB. The alternate conformations of side 322 chains were generally all visible in a conventional refinement without qFit and Ringer analysis. 323 From the current study it was not possible to get additional insight into the structural dynamics 324 that were suggested from previous NMR relaxation data and assumed to include conformational 325 changes on the millisecond time scale around the substrate binding site. Such slow conformational changes have for many enzymes been linked to either substrate binding or the catalytic mechanism and we found it reasonable to hypothesise that such conformation changes

328 329 330

\section{Conclusions}

346 Our aim was to assess if the conformational dynamics previously observed by NMR relaxation would also be present in Savinase, in particular around the substrate binding site as suggested by NMR relaxation (Remerowski et al., 1996). However, the absence of alternative conformations is consistent with the very similar conformations of the homologue subtilisin BPN' with and without the inhibitor protein chymotrypsin inhibitor 2 (Gallagher et al., 1996; Radisky \& Koshland, 2002). Even the loops covering the active site have almost identical conformations in these two structures.

Intrinsic microsecond-millisecond motions in e.g. adenylate cyclase are associated with large loop movements although conformational changes in e.g. protein tyrosine phosphatase 1B, RNase A and dihydrofolate reductase are of smaller amplitude (Beach et al., 2005; Boehr et al., 2010; Whittier, Hengge \& Loria, 2013). Collectively these fluctuations allow for substrates and products to access or leave the active site. In these enzymes the conformational changes necessary for binding and release of the substrate and product are rate-limiting for catalysis. In Savinase, the active site is more accessible, and no substantial structural changes are needed for substrate binding. This behaviour is similar to human glutaredoxin (Jensen, Winther \& Teilum, 2011) and may explain why no conformational exchange is observed in the ground state of Savinase and suggest that substrate binding follows an induced fit like mechanism. gave rise to a well-defined minor conformational state. The qFit and Ringer analysis of the crystallographic data did not identify significant minor conformations in this rather rigid enzyme 
349 structure. The other techniques applied also did not identify such alternative states, although 350 there is more flexibility in the loops surrounding the active site than in the remainder of the 351 protein. However, very low populated conformations that require more sensitive methods like 352 NMR relaxation (Kay, 2016) and single molecule FRET (Hatzakis et al., 2012) can of course still 353 be present.

354

\section{Acknowledgements}

356 KDR and KT are members of Integrative Structural Biology at the University of Copenhagen

357 (www.isbuc.ku.dk). Diamond Light Source is acknowledged for access to beamlines I03 and I04 358 (proposal number mx-9948) that contributed to the results presented here. The authors thank Sam 359 Hart for assistance during data collection. 


\section{References}

362 Baxter NJ, Williamson MP. 1997. Temperature dependence of $1 \mathrm{H}$ chemical shifts in proteins. $363 \quad$ Journal of biomolecular NMR 9:359-369.

364 Beach H, Cole R, Gill ML, Loria JP. 2005. Conservation of $\mu$ s-ms Enzyme Motions in the Apo365 and Substrate-Mimicked State. Journal of the American Chemical Society 127:91679176. DOI: $10.1021 / \mathrm{ja} 0514949$.

Betzel C, Dauter Z, Dauter M, Ingelman M, Papendorf G, Wilson KS, Branner S. 1988. Crystallization and preliminary $\mathrm{X}$-ray diffraction studies of an alkaline protease from Bacillus lentus. Journal of Molecular Biology 204:803-804. DOI: 10.1016/00222836(88)90372-5.

Betzel C, Klupsch S, Papendorf G, Hastrup S, Branner S, Wilson KS. 1992. Crystal structure of the alkaline proteinase Savinase from Bacillus lentus at 1.4 A resolution. 223:427-445.

373

374

375

376

377

378

379

380

381

382

383

384

385

386

Boehr DD, McElheny D, Dyson HJ, Wright PE. 2010. Millisecond timescale fluctuations in dihydrofolate reductase are exquisitely sensitive to the bound ligands. Proceedings of the National Academy of Sciences 107:1373-1378. DOI: 10.1073/pnas.0914163107.

Delaglio F, Grzesiek S, Vuister GW, Zhu G, Pfeifer J, Bax A. 1995. NMRPipe: a multidimensional spectral processing system based on UNIX pipes. Journal of biomolecular NMR 6:277-293.

Doyle CM, Rumfeldt JA, Broom HR, Sekhar A, Kay LE, Meiering EM. 2016. Concurrent Increases and Decreases in Local Stability and Conformational Heterogeneity in Cu, Zn Superoxide Dismutase Variants Revealed by Temperature-Dependence of Amide Chemical Shifts. Biochemistry 55:1346-1361.

Eisenmesser EZ. 2002. Enzyme Dynamics During Catalysis. Science 295:1520-1523. DOI: 10.1126/science.1066176.

Engen JR. 2009. Analysis of Protein Conformation and Dynamics by Hydrogen/Deuterium Exchange MS. Analytical Chemistry 81:7870-7875. DOI: 10.1021/ac901154s. 
387 Evans PR, Murshudov GN. 2013. How good are my data and what is the resolution? Acta

388

389

390

391

392

393

394

395

396

397

398

399

400

401

402

403

404

405

406

407

408

409

410

411

Crystallographica. Section D, Biological Crystallography 69:1204-1214. DOI: 10.1107/S0907444913000061.

Fast CS, Vahidi S, Konermann L. 2017. Changes in Enzyme Structural Dynamics Studied by Hydrogen Exchange-Mass Spectrometry: Ligand Binding Effects or Catalytically Relevant Motions? Analytical Chemistry 89:13326-13333. DOI: 10.1021/acs.analchem.7b03506.

Fogh RH, Schipper D, Boelens R, Kaptein R. 1995. Complete 1H, 13C and 15N NMR assignments and secondary structure of the 269-residue serine protease PB92 from Bacillus alcalophilus. Journal of biomolecular NMR 5:259-270.

Frankaer CG, Moroz OV, Turkenburg JP, Aspmo SI, Thymark M, Friis EP, Stahl K, Nielsen JE, Wilson KS, Harris P. 2014. Analysis of an industrial production suspension of Bacillus lentus subtilisin crystals by powder diffraction: a powerful quality-control tool. Acta Crystallographica Section D Biological Crystallography 70:1115-1123. DOI: 10.1107/S1399004714001497.

Fraser JS, van den Bedem H, Samelson AJ, Lang PT, Holton JM, Echols N, Alber T. 2011. Accessing protein conformational ensembles using room-temperature X-ray crystallography. Proceedings of the National Academy of Sciences of the United States of America 108:16247-16252.

Fraser JS, Clarkson MW, Degnan SC, Erion R, Kern D, Alber T. 2009. Hidden alternative structures of proline isomerase essential for catalysis. Nature 462:669-673.

Gallagher T, Oliver J, Bott R, Betzel C, Gilliland GL. 1996. Subtilisin BPN' at 1.6 Å Resolution: Analysis for Discrete Disorder and Comparison of Crystal Forms. Acta Crystallographica Section D Biological Crystallography 52:1125-1135. DOI: 10.1107/S0907444996007500. 
412 Graycar T, Knapp M, Ganshaw G, Dauberman J, Bott R. 1999. Engineered Bacillus lentus $413 \quad$ subtilisins having altered flexibility. 292:97-109.

414 Hageman TS, Weis DD. 2019. A Structural Variant Approach for Establishing a Detection Limit 415 in Differential Hydrogen Exchange-Mass Spectrometry Measurements. Analytical $416 \quad$ Chemistry 91:8017-8024. DOI: 10.1021/acs.analchem.9b01326.

417 Halle B. 2004. Biomolecular cryocrystallography: Structural changes during flash-cooling.

418 Proceedings of the National Academy of Sciences 101:4793-4798. DOI:

$419 \quad$ 10.1073/pnas.0308315101.

420 Hatzakis NS, Wei L, Jorgensen SK, Kunding AH, Bolinger P-Y, Ehrlich N, Makarov I, Skjot M,

421 Svendsen A, Hedegård P, Stamou D. 2012. Single Enzyme Studies Reveal the

422 Existence of Discrete Functional States for Monomeric Enzymes and How They Are

423

424 "Selected" upon Allosteric Regulation. Journal of the American Chemical Society 134:9296-9302.

Jensen PF, Rand KD. 2016. Hydrogen Exchange: A Sensitive Analytical Window into Protein 426 Conformation and Dynamics. In: Weis DD ed. Hydrogen Exchange Mass Spectrometry

427 of Proteins. Chichester, UK: John Wiley \& Sons, Ltd, 1-17. DOI:

428 10.1002/9781118703748.ch1.

Jensen KS, Winther JR, Teilum K. 2011. Millisecond dynamics in glutaredoxin during catalytic 430 turnover is dependent on substrate binding and absent in the resting states. Journal of the American Chemical Society 133:3034-3042.

Jones DD. 2011. Recombining low homology, functionally rich regions of bacterial subtilisins by combinatorial fragment exchange. PloS one 6:e24319-e24319.

Kabsch W. 2010. XDS. Acta Crystallographica. Section D, Biological Crystallography 66:125132. DOI: $10.1107 / S 0907444909047337$.

Kay LE. 2016. New Views of Functionally Dynamic Proteins by Solution NMR Spectroscopy. Journal of Molecular Biology 428:323-331. DOI: 10.1016/j.jmb.2015.11.028. 
438 Keedy DA, Fraser JS, van den Bedem H. 2015. Exposing Hidden Alternative Backbone

439

440

441

442

443

444

445

446

447

448

449

450

451

452

453

454

455

456

457

458

459

460

461

462

Conformations in X-ray Crystallography Using qFit. PLOS Computational Biology 11:e1004507. DOI: 10.1371/journal.pcbi.1004507.

Lang PT, Ng H-L, Fraser JS, Corn JE, Echols N, Sales M, Holton JM, Alber T. 2010. Automated electron-density sampling reveals widespread conformational polymorphism in proteins. Protein science : a publication of the Protein Society 19:1420-1431.

Liebschner D, Afonine PV, Baker ML, Bunkóczi G, Chen VB, Croll TI, Hintze B, Hung L-W, Jain S, McCoy AJ, Moriarty NW, Oeffner RD, Poon BK, Prisant MG, Read RJ, Richardson JS, Richardson DC, Sammito MD, Sobolev OV, Stockwell DH, Terwilliger TC, Urzhumtsev AG, Videau LL, Williams CJ, Adams PD. 2019. Macromolecular structure determination using X-rays, neutrons and electrons: recent developments in Phenix. Acta Crystallographica Section D Structural Biology 75:861-877. DOI: 10.1107/S2059798319011471.

Martin JR, Mulder FA, Karimi-Nejad Y, van der Zwan J, Mariani M, Schipper D, Boelens R. 1997. The solution structure of serine protease PB92 from Bacillus alcalophilus presents a rigid fold with a flexible substrate-binding site. Structure (London, England: 1993) $5: 521-532$

Masson GR, Burke JE, Ahn NG, Anand GS, Borchers C, Brier S, Bou-Assaf GM, Engen JR, Englander SW, Faber J, Garlish R, Griffin PR, Gross ML, Guttman M, Hamuro Y, Heck AJR, Houde D, lacob RE, Jørgensen TJD, Kaltashov IA, Klinman JP, Konermann L, Man P, Mayne L, Pascal BD, Reichmann D, Skehel M, Snijder J, Strutzenberg TS, Underbakke ES, Wagner C, Wales TE, Walters BT, Weis DD, Wilson DJ, Wintrode PL, Zhang Z, Zheng J, Schriemer DC, Rand KD. 2019. Recommendations for performing, interpreting and reporting hydrogen deuterium exchange mass spectrometry (HDX-MS) experiments. Nature Methods 16:595-602. DOI: 10.1038/s41592-019-0459-y. 
463 Masterson LR, Cembran A, Shi L, Veglia G. 2012. Allostery and Binding Cooperativity of the

464

465

466

467

468

469

470

471

472

473

474

475

476

477

478

479

480

481

482

483

484

485

486

487

488

Catalytic Subunit of Protein Kinase A by NMR Spectroscopy and Molecular Dynamics Simulations. In: Advances in Protein Chemistry and Structural Biology. Elsevier, 363389. DOI: 10.1016/B978-0-12-398312-1.00012-3.

Möller IR, Slivacka M, Nielsen AK, Rasmussen SGF, Gether U, Loland CJ, Rand KD. 2019. Conformational dynamics of the human serotonin transporter during substrate and drug binding. Nature Communications 10. DOI: 10.1038/s41467-019-09675-z.

Mulder FA, Schipper D, Bott R, Boelens R. 1999. Altered flexibility in the substrate-binding site of related native and engineered high-alkaline Bacillus subtilisins. Journal of Molecular Biology 292:111-123. DOI: 10.1006/jmbi.1999.3034.

Newman J, Egan D, Walter TS, Meged R, Berry I, Ben Jelloul M, Sussman JL, Stuart DI, Perrakis A. 2005. Towards rationalization of crystallization screening for small- to medium-sized academic laboratories: the PACT/JCSG+ strategy. Acta Crystallographica. Section D, Biological Crystallography 61:1426-1431. DOI: 10.1107/S0907444905024984.

Nielsen AK, Möller IR, Wang Y, Rasmussen SGF, Lindorff-Larsen K, Rand KD, Loland CJ. 2019. Substrate-induced conformational dynamics of the dopamine transporter. Nature Communications 10. DOI: 10.1038/s41467-019-10449-w.

Pandya MJ, Schiffers S, Hounslow AM, Baxter NJ, Williamson MP. 2018. Why the Energy Landscape of Barnase Is Hierarchical. Frontiers in Molecular Biosciences 5:115. DOI: 10.3389/fmolb.2018.00115.

Radisky ES, Koshland DE. 2002. A clogged gutter mechanism for protease inhibitors. Proceedings of the National Academy of Sciences of the United States of America 99:10316-10321.

Remerowski ML, Domke T, Groenewegen A, Pepermans HA, Hilbers CW, Van De Ven FJ. 1994. 1H, 13C and 15N NMR backbone assignments and secondary structure of the 
489

490

491

492

493

494

495

496

497

498

499

500

501

502

503

504

505

506

507

508

509

510

511

512

513

269-residue protease subtilisin 309 from Bacillus lentus. Journal of biomolecular NMR 4:257-278.

Remerowski ML, Pepermans HA, Hilbers CW, Van De Ven FJ. 1996. Backbone dynamics of the 269-residue protease Savinase determined from 15N-NMR relaxation measurements. European journal of biochemistry / FEBS 235:629-640.

Saio T, Kawagoe S, Ishimori K, Kalodimos CG. 2018. Oligomerization of a molecular chaperone modulates its activity. eLife 7. DOI: 10.7554/eLife.35731.

Schechter I, Berger A. 1967. On the size of the active site in proteases. I. Papain. Biochemical and Biophysical Research Communications 27:157-162. DOI: 10.1016/s0006$291 x(67) 80055-x$.

Skinner SP, Fogh RH, Boucher W, Ragan TJ, Mureddu LG, Vuister GW. 2016. CcpNmr AnalysisAssign: a flexible platform for integrated NMR analysis. Journal of biomolecular NMR:1-14.

Teilum K, Poulsen FM, Akke M. 2006. The inverted chevron plot measured by NMR relaxation reveals a native-like unfolding intermediate in acyl-CoA binding protein. Proceedings of the National Academy of Sciences of the United States of America 103:6877-82.

Tindbaek N, Svendsen A, Oestergaard PR, Draborg H. 2004. Engineering a substrate-specific cold-adapted subtilisin. Protein Engineering, Design and Selection 17:149-156. DOI: 10.1093/protein/gzh019.

Tomlinson JH, Williamson MP. 2012. Amide temperature coefficients in the protein G B1 domain. Journal of biomolecular NMR 52:57-64.

Trabjerg E, Nazari ZE, Rand KD. 2018. Conformational analysis of complex protein states by hydrogen/deuterium exchange mass spectrometry (HDX-MS): Challenges and emerging solutions. TrAC Trends in Analytical Chemistry 106:125-138. DOI:

10.1016/j.trac.2018.06.008. 
514 Verteramo ML, Stenström O, Ignjatović MM, Caldararu O, Olsson MA, Manzoni F, Leffler H, 515 Oksanen E, Logan DT, Nilsson UJ, Ryde U, Akke M. 2019. Interplay between

516 Conformational Entropy and Solvation Entropy in Protein-Ligand Binding. Journal of the 517 American Chemical Society 141:2012-2026. DOI: 10.1021/jacs.8b11099.

518 Whittier SK, Hengge AC, Loria JP. 2013. Conformational motions regulate phosphoryl transfer 519 in related protein tyrosine phosphatases. Science (New York, N.Y.) 341:899-903.

520 Williamson MP. 2003. Many residues in cytochrome c populate alternative states under 521 equilibrium conditions. Proteins 53:731-739. DOI: 10.1002/prot.10464.

522 Wolf-Watz M, Kay LE, Kern D. 2005. Intrinsic dynamics of an enzyme underlies catalysis. $523 \quad$ Nature 438:117-121.

524 


\section{Figure 1}

Temperature induced chemical shift changes in Savinase.

(A) ${ }^{15} \mathrm{~N}$-HSQC spectra recorded at $18{ }^{\circ} \mathrm{C}, 22{ }^{\circ} \mathrm{C}, 26{ }^{\circ} \mathrm{C}, 30^{\circ} \mathrm{C}$ and $34{ }^{\circ} \mathrm{C}$ in colours from light to dark red. (B) Temperature coefficients for the backbone amide proton chemical shifts plotted against sequence number. The dashed lines show the average temperature coefficient (Avg) and one standard deviation (- $\sigma$ ). (C) The structure of Savinase is colour coded according to the temperature coefficients shown in panel B. The colour scale is shown to the right of the structure. The metals as shown as spheres, $\mathrm{Ca}^{2+}$ (grey) and $\mathrm{Na}^{+}$(orange). The catalytic triad in the active site is shown with spheres. 

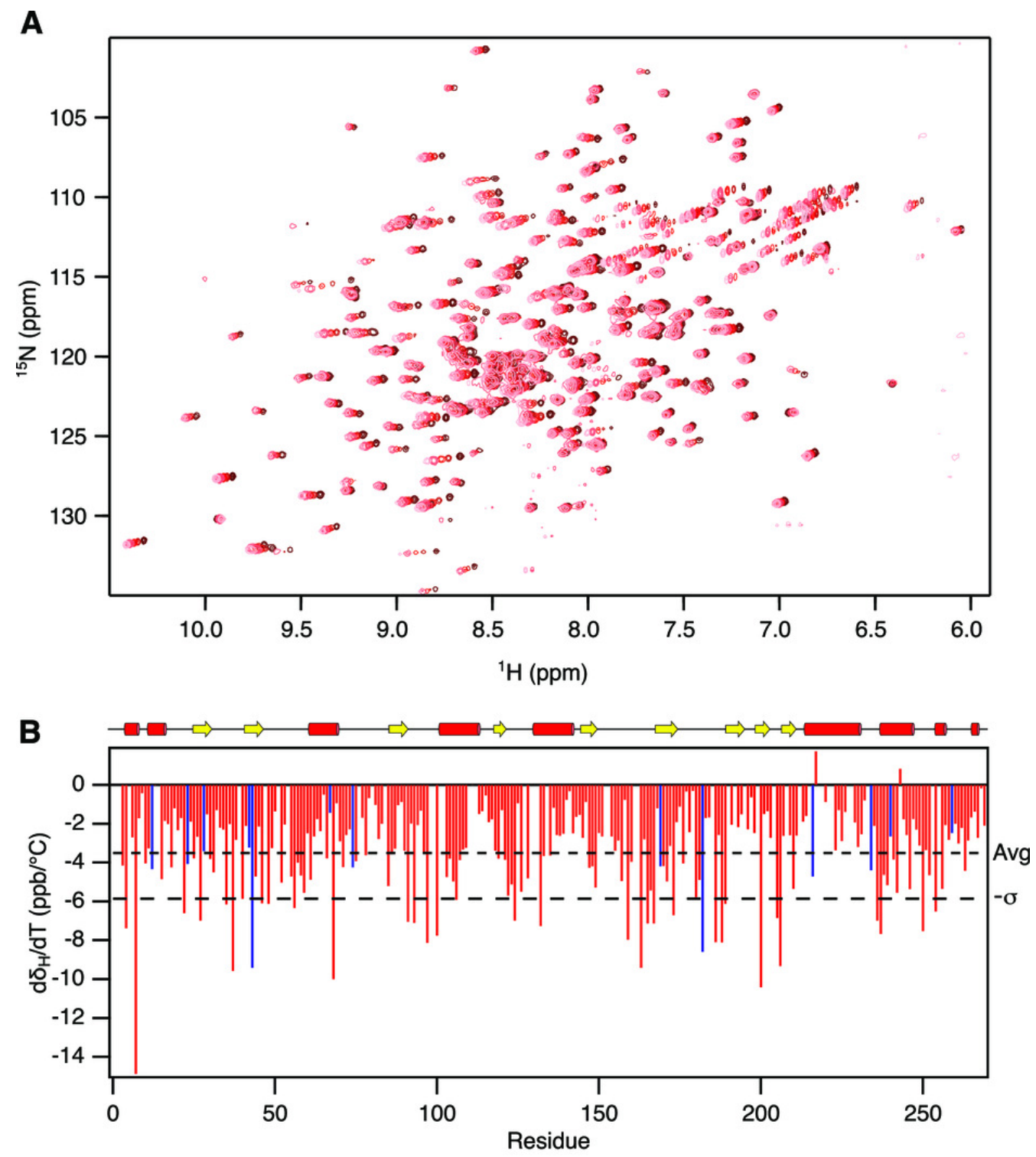

C

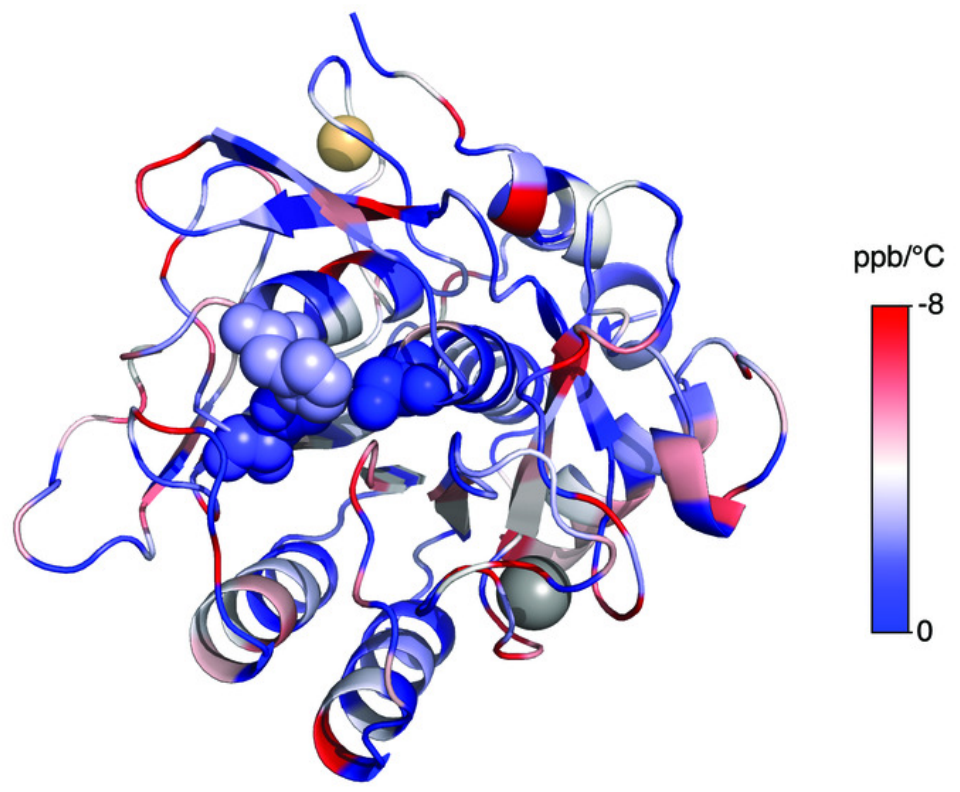




\section{Figure 2}

HDX analysis of Savinase.

(A-C) Time dependent changes in deuterium content for three peptide fragments, as indicated in the lower right corner of each graph. Data for uninhibited and inhibited Savinase are shown in red and blue, respectively. Maximum labelled controls are shown in black. Error bars indicate standard deviations for time points measured in replicates ( $n=3)$. (D-E) Heat map overview of the normalized local HDX of different regions. The two maps are for uninhibited Savinase (D) and inhibited Savinase (E). The normalized HDX for the four time points indicated on the right are displayed for each peptide segment experimentally resolved on a colour scale from no HDX (blue) over white to full HDX (red).

A
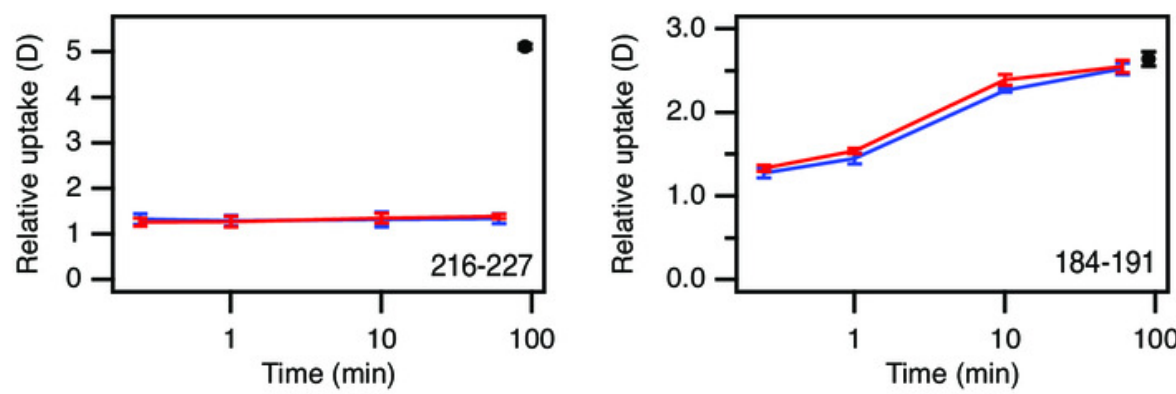

C

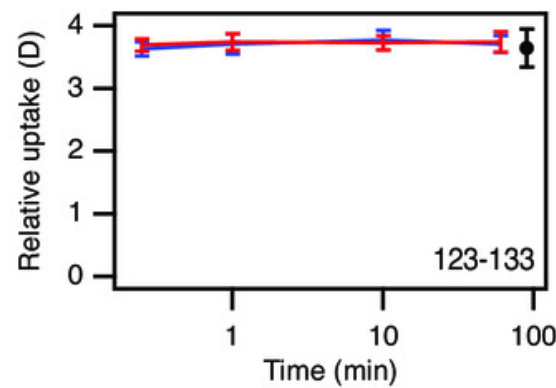

\section{D}

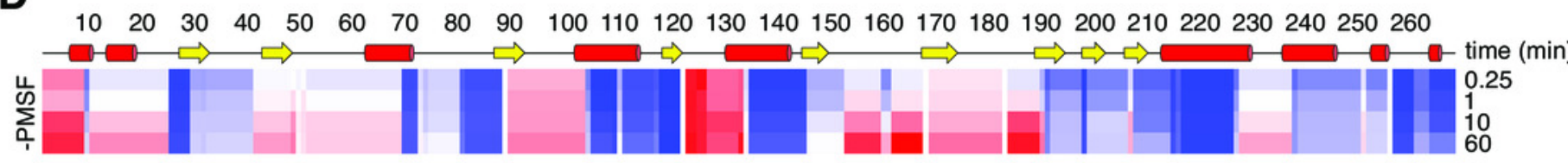

E
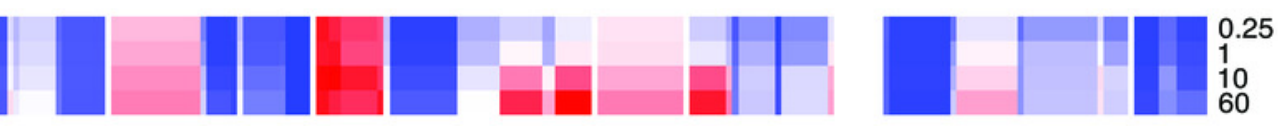


\section{Figure 3}

Alternative conformations in the electron density of Savinase.

(A) Main chain heterogeneity in the cryo data of the peptide segment 128-132 with the $2 \mathrm{mF}_{0}$ $\mathrm{DF}_{\mathrm{c}}$ electron density map plotted at $1 \sigma$. Residues 127 and 133 that only show a single conformation are also shown in the figure. (B) Ringer analysis of rotamers of Ser-215. The electron density is plotted as a function of the side-chain $\chi_{1}$ dihedral angle for the RT data (red) and the cryo data (blue). (C) Structure of Ser-215 and surrounding residues with the $2 \mathrm{mF}_{\mathrm{o}}-\mathrm{DF}_{\mathrm{c}}$ electron density map of the RT data plotted at $1 \sigma$. Two rotamers of the Ser-215 side chain with occupancies of $73 \%$ and $27 \%$ have been modelled to the electron density. 
A

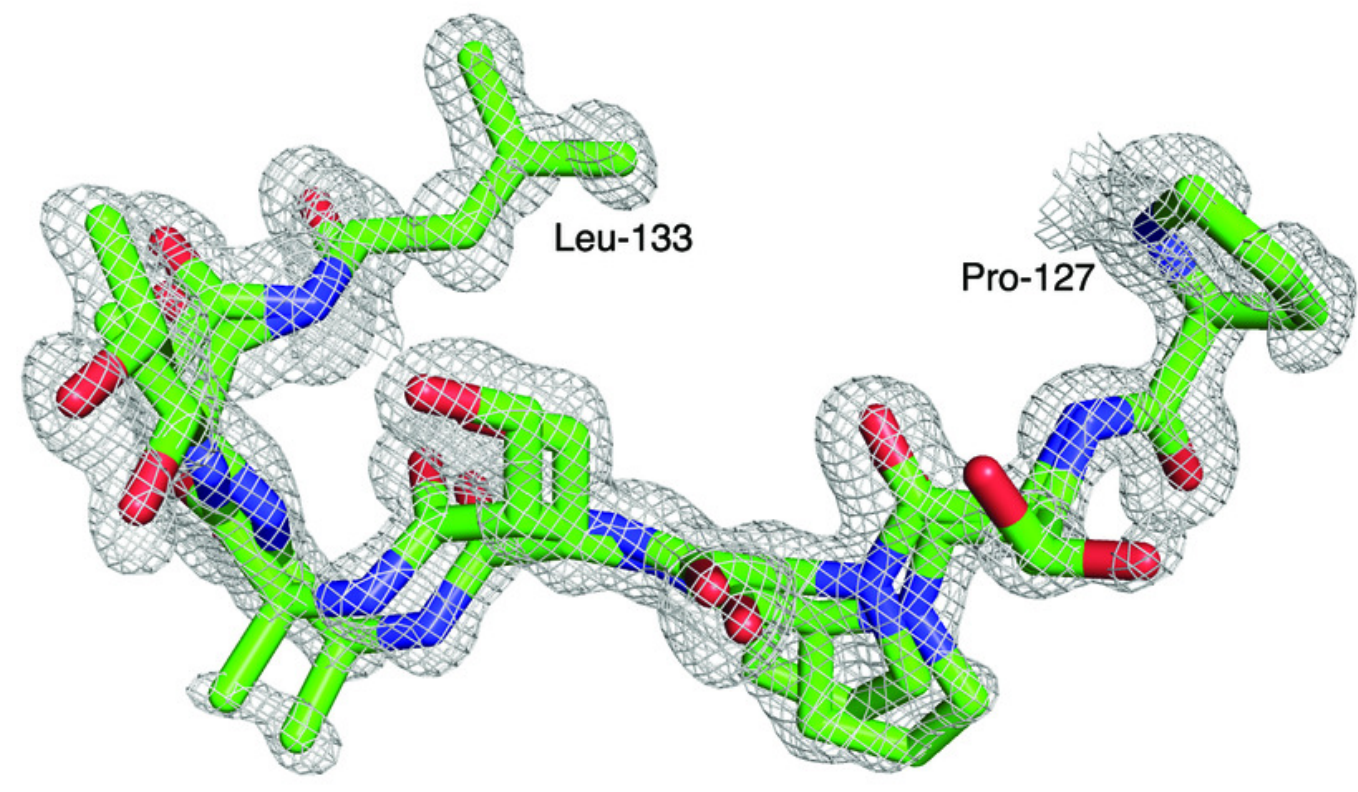

B

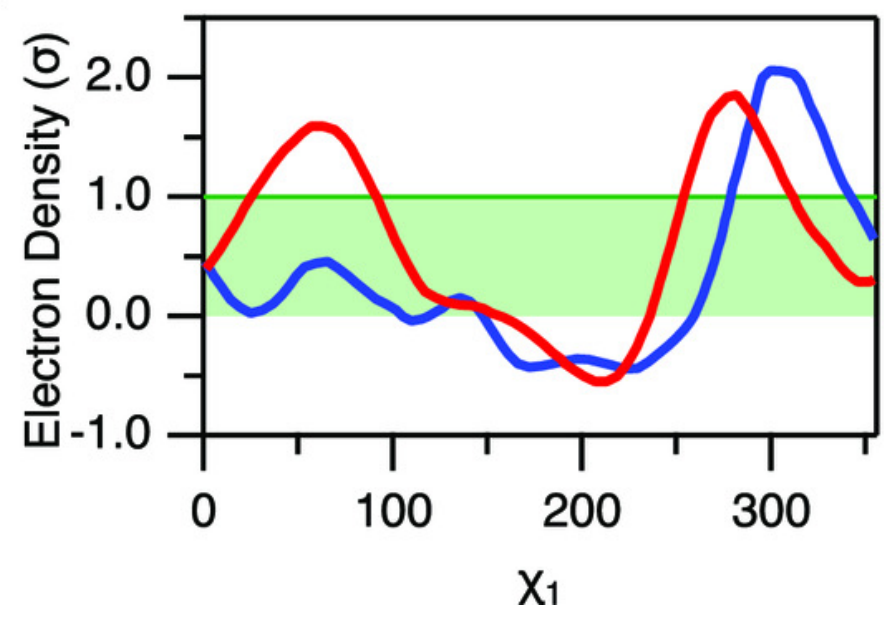

C

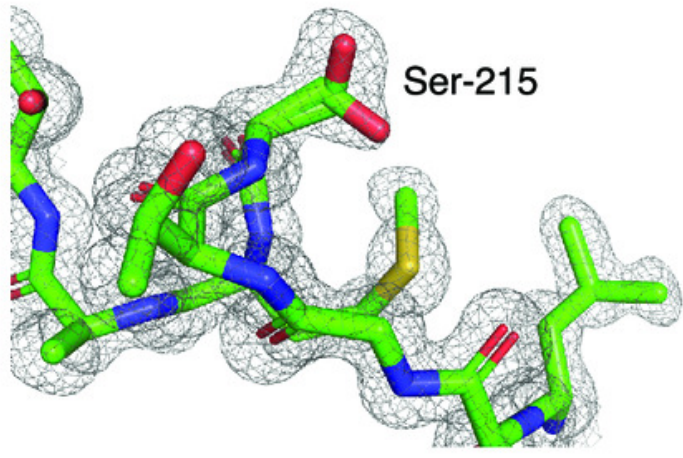


Figure 4

Structure of Savinase from the crystallographic data collected at room temperature.

The width of the backbone trace is scaled with the B-factor. The colour scale is from blue (0 $\AA^{2}$ ) over white to red $\left(35 \AA^{2}\right)$. The residues of the catalytic triad are shown as sticks.

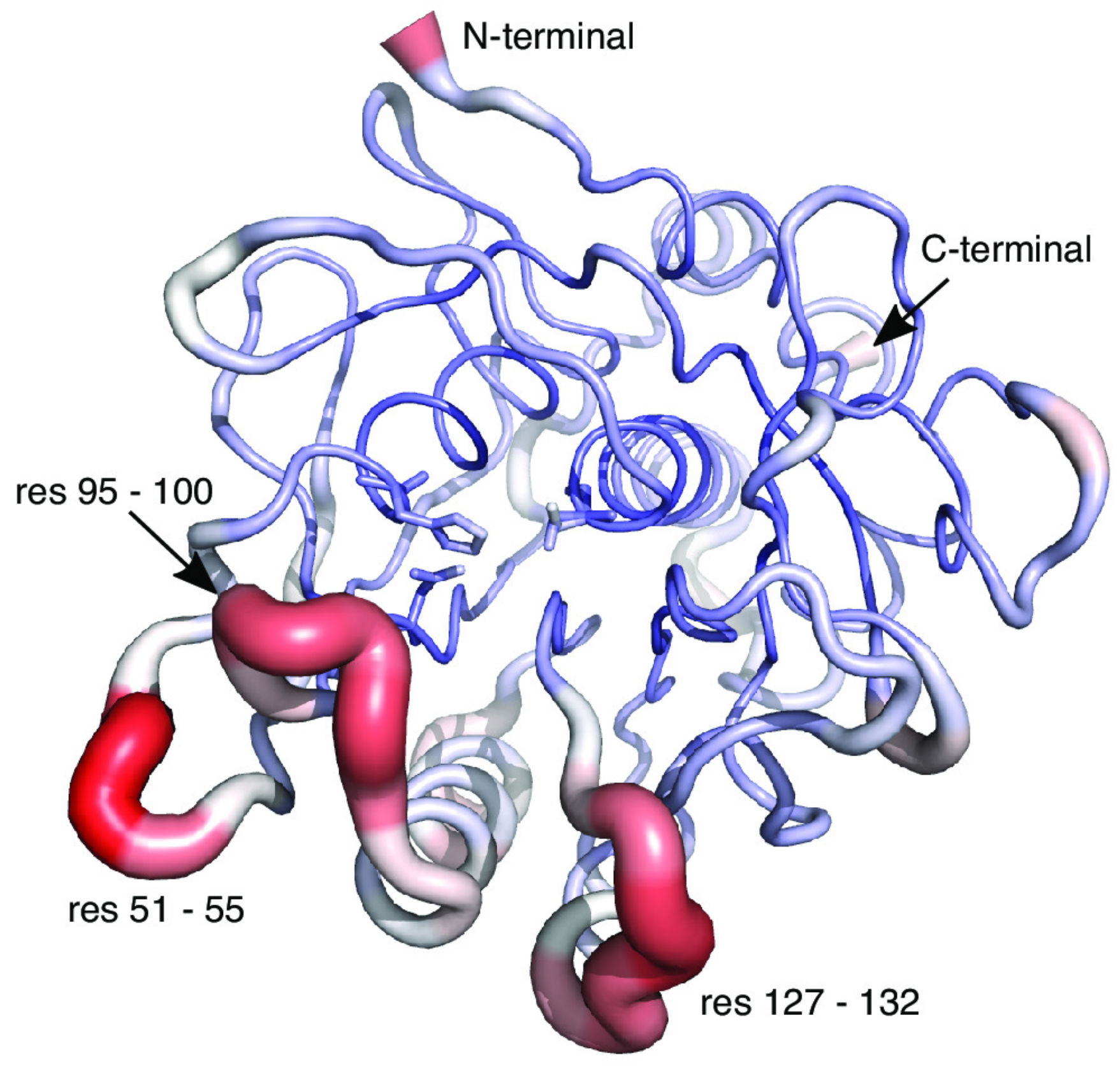

